\title{
PWM Rectifier Control Comparison for Aerospace Applications
}

Link to publication record in Manchester Research Explorer

\section{Citation for published version (APA):}

Todd, R., Liu, K., \& Lau, Y. (2014). PWM Rectifier Control Comparison for Aerospace Applications. In host publication

\section{Published in:}

host publication

\section{Citing this paper}

Please note that where the full-text provided on Manchester Research Explorer is the Author Accepted Manuscript or Proof version this may differ from the final Published version. If citing, it is advised that you check and use the publisher's definitive version.

\section{General rights}

Copyright and moral rights for the publications made accessible in the Research Explorer are retained by the authors and/or other copyright owners and it is a condition of accessing publications that users recognise and abide by the legal requirements associated with these rights.

\section{Takedown policy}

If you believe that this document breaches copyright please refer to the University of Manchester's Takedown Procedures [http://man.ac.uk/04Y6Bo] or contact uml.scholarlycommunications@manchester.ac.uk providing relevant details, so we can investigate your claim.

\section{OPEN ACCESS}


This paper was published at the IET Power Electronics, Machines and Drives (PEMD) Conference in April 2014, doi 10.1049/cp.2014.0427, and is available at:

http://ieeexplore.ieee.org/stamp/stamp.jsp?tp=\&arnumber=6836999

R. Todd, K. Liu, Y. Lau, "PWM Rectifier Control Comparison for Aerospace Applications," 7th IET International Conference on Power Electronics, Machines and Drives (PEMD), April 2014, doi: 10.1049/cp.2014.0427

(C) 2014 IET. Personal use of this material is permitted. Permission from the IET must be obtained for all other uses, in any current or future media, including reprinting/republishing this material for advertising or promotional purposes, creating new collective works, for resale or redistribution to servers or lists, or reuse of any copyrighted component of this work in other works. 


\title{
PWM Rectifier Control Comparison for Aerospace Applications
}

\author{
R. Todd, K. Liu, Y. Lau \\ School of Electrical and Electronic Engineering, The University of Manchester, UK \\ rebecca.todd@manchester.ac.uk
}

Keywords: PWM rectifier, averaged-value modelling, model predictive control, DC-bus power quality

\begin{abstract}
High-voltage DC-bus power quality is examined when the power network is supplied by a PWM rectifier controlled using different DC-bus voltage regulation schemes. Three controllers are compared, a voltage oriented control and two model predictive control schemes, predictive current fixed frequency and predictive direct power control. A set of PWM rectifier simulation models illustrate the performance of the controllers; a switched model, an ideal averaged-value model and an enhanced averaged-value model which contains the key loss mechanisms. The DC-bus transients are within the limits defined in MIL-STD-704F only when a predictive direct power control is employed.
\end{abstract}

\section{Introduction}

Advanced more-electric-aircrafts (MEAs) are anticipated to have multiple gas-engine driven variable frequency generators [1] and high levels of diverse, highly-dynamic, and often safety critical, power electronics based load systems interconnected through a single power network. DC power network architectures are a contender for future MEA [1] as the power conversion stages and the paralleling of multiple power sources is less complex than an equivalent AC network, however, challenges still exist, including protection and network power quality. A candidate power network architecture for future aircraft is higher voltage DC, either a single $270 \mathrm{~V}$ channel or $\pm 270 \mathrm{~V}$.

Strict limits are defined in the MIL-Std704F [2] on the allowable steady-state and transient DC network voltage. To achieve the DC-bus power quality defined in MIL-Std-704F, one solution is to use a power electronic interface between the gas-engine embedded variable speed generator and the network. For fixed nominal voltage DC networks a PWM boost rectifier [3] is a candidate interface converter.

A SABER simulation model of a $10 \mathrm{~kW} 270 \mathrm{~V}$ DC three-phase PWM rectifier is used to evaluate the different models/controllers. In Fig. 1 three rectifier models can be used; a switched model, and either an ideal [4] or enhanced averaged-value models. The enhanced averaged-value PWM rectifier model includes the key circuit loss mechanisms, including device conduction and switching, and non-linear effects (dead-time and over-modulation) which may affect the circuit efficiency.

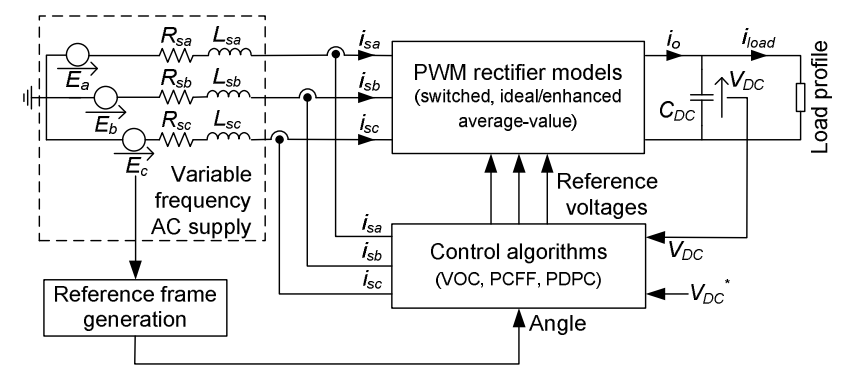

Figure 1. System configuration.

Multiple DC voltage controllers have been applied to Fig. 1; vector oriented control (VOC), predictive current fixed frequency (PCFF) [5] and predictive direct power control (PDPC) [6]. The three DC voltage control strategies are examined with a focus on unity AC power factor, DC power quality (voltage deviation) and circuit efficiency for a range of typical aircraft load systems.

The system in Fig. 1 is part of a larger suite of models which have been developed in an EU JTI Clean Sky project to enable investigations to be undertaken into the behaviour and energy efficiency of alternative electric drive solutions and technologies over a range of aircraft electrical system architectures and operating scenarios.

In the following sections the ideal and enhanced averagedvalue model equations are briefly discussed and simulation results are presented to examine the performance of the models. The design of the different DC-bus voltage regulators is then presented and simulation results are used to illustrate the performance of the controllers.

\section{PWM Rectifier Model}

The structure of the six-switch three-phase PWM boost rectifier which is used to energise the aircraft DC network is shown in Fig. 2.

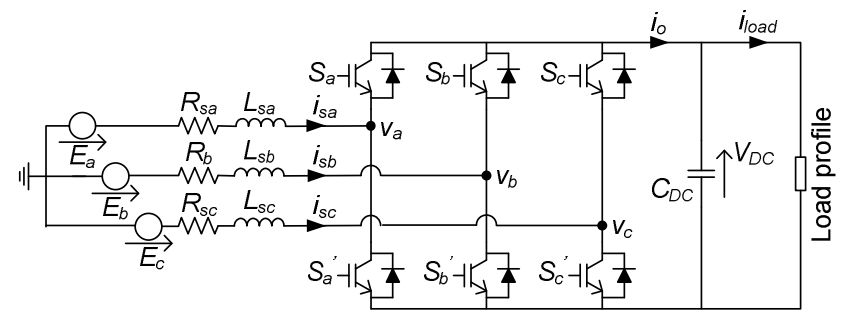

Figure 2. Three-phase PWM rectifier switched model.

Averaged-value models of the PWM rectifier are developed to allow the converter performance over long duration load 
profiles to be evaluated with an acceptable computation time.

\subsection{Ideal averaged-value}

The ideal averaged-value model [4] synthesises the mid-point voltage of each rectifier leg, $v_{a}, v_{b}, v_{c}$, shown in Fig. 2, to produce an equivalent DC voltage which is imposed across the output capacitor. The DC side is a current sink, due to the voltage imposed across the output impedance (capacitor and load), and so the rectifier is a current source from the AC side.

Equation (1) can be used to define the per-phase duty cycle, $d_{z}$, where ' $z$ ' in (1) can be either $\mathrm{a}, \mathrm{b}$ or $\mathrm{c}$.

$$
d_{z}=\frac{1+m_{z}}{2} \sin (\omega t-\delta-x)
$$

$m_{z}$ is the depth of modulation, $\delta$ is the phase shift between the AC supply and the input to the rectifier half-bridge, $\omega$ is the supply frequency and ' $x$ ' is the $120^{\circ}$ phase shift between each phase. Assuming the use of bipolar naturally sampled PWM, then to ensure the rectifier operates in the linear region (to avoid over-modulation), $m_{z}$ is limited to unity.

By considering the volt-seconds of the mid-point voltage of each rectifier leg, averaged-value rectifier leg voltages $v_{a}, v_{b}, v_{c}$ can be expressed as functions of the respective duty cycle, so:

$$
v_{z}=\frac{\left(2 d_{z}-1\right)}{2} V_{D C}=\frac{m_{z} V_{D C}}{2} \sin (\omega t-\delta-x)
$$

The AC current per-phase can be written as:

$$
i_{s z}=I_{s Z} \sin (\omega t-\varphi-x)
$$

where $\varphi$ is the angle between the per-phase AC voltage, $v_{z}$, and current, $i_{s z}$.

If the three-phase PWM rectifier is assumed lossless, then power input to the bridge is equal to the power delivered to the output side. Eq. (2) can then be substituted in the power balance equation to give an expression for the DC output current, (4).

$$
i_{O}=\sum\left(\left[d_{z}-\frac{1}{2}\right] i_{s z}\right)
$$

\subsection{Enhanced averaged-value}

The ideal averaged-value rectifier model is enhanced to include the dominant features of a practical PWM rectifier which may affect the system level performance of the power converter. The loss mechanisms which are considered are IGBT and diode conduction voltage drops, switching losses and deadtime. The circuit losses are defined using simple expressions based on parameters readily available in component datasheets.

\section{Conduction losses and dead-time}

The conduction losses are calculated by approximating the device voltage drop as a threshold voltage and a voltage across the internal resistance [7]. Therefore, the voltage drop across the IGBT and diode can be expressed by (5) and (6) respectively. The current component in (5) and (6) is taken as an absolute value as unidirectional IGBT's are considered.

$$
v_{I G B T}=v_{t h-I G B T}+\left|i_{S Z}\right| R_{I G B T}
$$

$$
v_{\text {diode }}=v_{\text {th-diode }}+\left|i_{s z}\right| R_{\text {diode }}
$$

where $v_{t h-I G B T}$ and $v_{\text {th-diode }}$ are the IGBT and diode threshold voltages and $R_{I G B T}$ and $R_{\text {diode }}$ are the IGBT and diode internal resistances.

Dead-time is an essential feature of most practical power converters to prevent damage to the power devices. When dead-time is incorporated in the averaged-value model equations the polarity of the AC current determines how deadtime affects the phase voltage and DC output current.

Equations (5) and (6), together with the effect of dead-time, $D$, both need to be integrated with (2) by summing the voltseconds for the averaged phase voltage over a switching period, $T_{s w}$. The expression for the phase voltage, $v_{z}$, during positive AC current is given by (7), and (8) for negative AC current.

$$
\begin{gathered}
v_{z}=\left[2\left(d_{z}+D_{D T}\right)-1\right] \frac{V_{D C}}{2}+\left(d_{z}+D_{D T}\right) v_{\text {diode }}+[1- \\
\left.\left(d_{z}+D_{D T}\right)\right] v_{I G B T} \\
v_{z}=\left[2\left(d_{z}-D_{D T}\right)-1\right] \frac{V_{D C}}{2}-\left[1-\left(d_{z}-D_{D T}\right)\right] v_{\text {diode }}- \\
\left(d_{z}-D_{D T}\right) v_{I G B T}+
\end{gathered}
$$

where $D_{D T}$ is the ratio of dead-time, $D$, to switching period, $T_{S w} ; D_{D T}=\frac{D}{T_{S W}}$.

Dead-time also affects the DC current contribution per-phase, to account for this (4) must be modified by considering the device conduction. Equations (9) and (10), for positive and negative AC current respectively, are the per-phase output current contributions including dead-time which must be summed to form the total DC output current.

$$
\begin{aligned}
& i_{O}=\left(d_{z}+D_{D T}-\frac{1}{2}\right) i_{s z} \\
& i_{O}=\left(d_{z}-D_{D T}-\frac{1}{2}\right) i_{S Z}
\end{aligned}
$$

\section{Switching losses}

Switching losses are produced when hard switching of the power devices is used. The switching losses are a function of device turn-on, $E_{O N}$, and turn-off energy, $E_{O F F}$, and switching frequency, $f_{S w}$ [7]. Datasheets often quote a figure for turn-on and turn-off energy for a single test point, $V_{D C-N o m}, i_{N o m}$, which sums the IGBT and diodes losses so a simple linear scaling is used to map the losses to other operating points, $V_{D C}$, $i_{O}$. The scaled switching losses per-phase are given by:

$P_{S W}=\sum\left(E_{O N} \frac{V_{D C}}{V_{D C-N o m}} \frac{i_{O}}{i_{N o m}}+E_{O F F} \frac{V_{D C}}{V_{D C-N o m}} \frac{i_{O}}{i_{\text {Nom }}}\right) f_{S w}$

The switching power loss can be calculated for all phases and summed to give the total power loss. This power can be converted to a DC current component, by dividing by the DC voltage, and the current component can then be combined with the total DC output current.

\subsection{Simulation result comparison}

The three PWM rectifier models, a switched, and ideal and enhanced (lossy) averaged-value, have been implemented in 
SABER software. A $10 \mathrm{~kW} 270 \mathrm{~V}$ rectifier is simulated and the $\mathrm{AC}$ and DC circuit parameters are listed in Table 1. The AC circuit is assumed balanced so all per-phase impedances are the same and the generator saliency is neglected. The rectifier has a relatively small value of DC-bus capacitance due to the requirement to avoid electrolytic capacitor types in aerospace systems. Two load conditions are examined, $14.58 \Omega(5 \mathrm{~kW})$ and $7.29 \Omega(10 \mathrm{~kW})$.

\begin{tabular}{|c|c|c|}
\hline Parameter description & Symbol & Value \\
\hline Back emf magnitude & $E$ & $0.0557 \mathrm{Vrads}^{-1}$ \\
\hline Nominal frequency & $f$ & $200 \mathrm{~Hz}$ \\
\hline Line inductance & $L_{S}$ & $0.4 \mathrm{mH}$ \\
\hline Line resistance & $R_{S}$ & $0.15 \mathrm{~m} \Omega$ \\
\hline Output capacitance & $C_{D C}$ & $800 \mu \mathrm{F}$ \\
\hline
\end{tabular}

Table 1. Test electrical system specification.

The devices used in the enhanced (lossy) averaged-value model are the $600 \mathrm{~V} 100 \mathrm{~A}$ Dawin IGBT module [8]; the parameters are listed in Table A.1 in Appendix A. The deadtime, $D$, is $2 \mu$ s and the switching frequency, $f_{s}$, is $10 \mathrm{kHz}$.

Each PWM rectifier model is commanded by a different dutycycle, defined in the figure, which gives $270 \mathrm{~V}$ in the ideal averaged-value model. Figs. 3 and 4 show sample results from all three PWM rectifier models. The top plots show DC voltage and the bottom plots back emf and AC current for phase a only; the other AC currents are omitted for clarity.
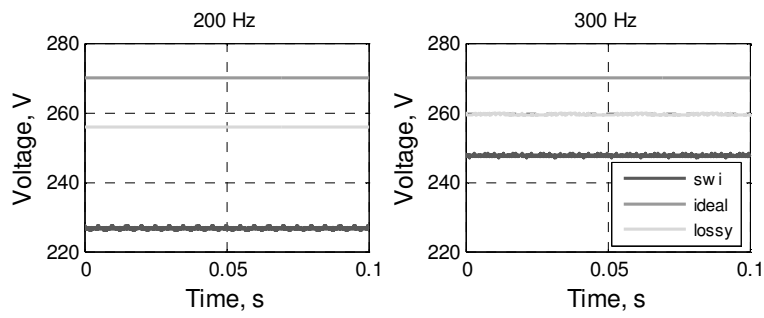

a. DC voltage
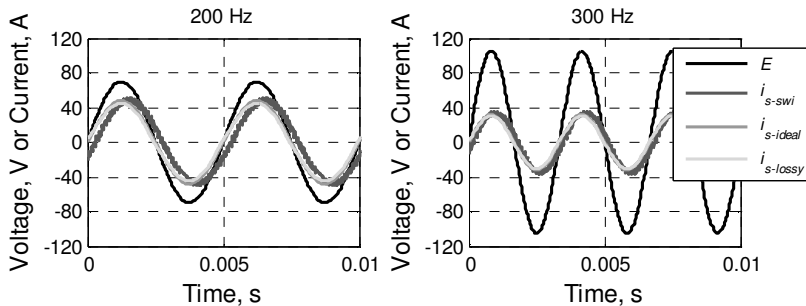

b. Back emf and AC current

Figure 3. Key waveforms for uncontrolled switched, ideal and enhanced (lossy) averaged-value models for a $14.58 \Omega$ load (at $200 \mathrm{~Hz}_{z}=0.546$ and $\delta=19.04^{\circ}$, at $300 \mathrm{~Hz} \mathrm{~m}=0.794$ and $\left.\delta=12.95^{\circ}\right)$.

The DC voltage, Figs. 3.a and 4.a, from all models correlate well for the test conditions examined. In all cases the DC voltage from the enhanced (lossy) model is slightly less than the ideal model due to the effect of the losses which requires adjustment to the duty-cycle to obtain the correct DC voltage. The difference in DC voltage from the enhanced and ideal model increases with load which is consistent with the efficiency being slightly lower in the higher load results. Figs. 3.b and 4.b shows AC current for a short time period to illustrate the detail of the three models. In the results shown all PWM rectifier models are operating at unity AC supply power factor. The lossy averaged-value PWM rectifier model efficiency with the $14.58 \Omega$ load is $96.1 \%$ for $200 \mathrm{~Hz}$ operation and $97.2 \%$ for $300 \mathrm{~Hz}$ operation.
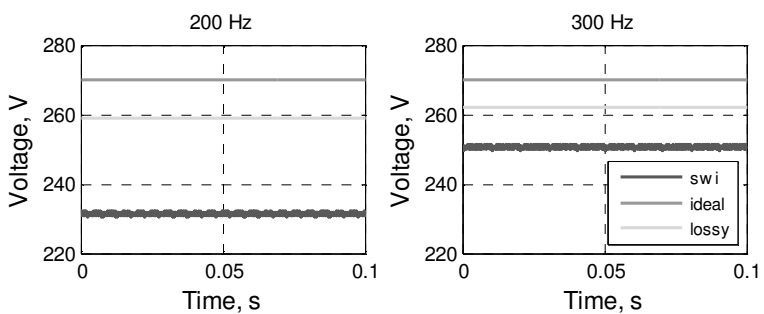

a. DC voltage
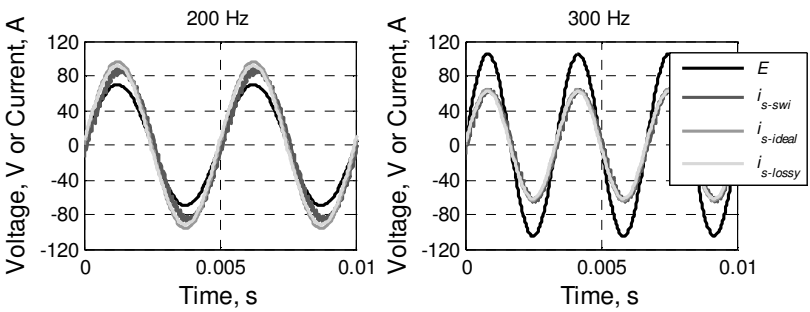

b. Back emf and AC current

Figure 4. Key waveforms for uncontrolled switched, ideal and enhanced (lossy) averaged-value models for a 7.29 $\Omega$ load (at $200 \mathrm{~Hz} m_{z}=0.626$ and $\delta=34.85^{\circ}$, at $300 \mathrm{~Hz} m_{z}=0.849$ and $\left.\delta=24.89^{\circ}\right)$.

For the $7.29 \Omega$ load condition in Fig. 4 the lossy averaged-value PWM rectifier model efficiency is $95.7 \%$ for $200 \mathrm{~Hz}$ operation and $96.8 \%$ for $300 \mathrm{~Hz}$ operation.

\section{Control Design}

This section presents an overview of three control techniques which enables the DC voltage to be regulated whilst also enabling the AC supply power factor to be controlled. Operation at unity $\mathrm{AC}$ side power factor is preferred, where the rectifier is controlled so the AC current, $i_{s z}$, is in phase with the back emf, $E_{z}$. The modulation limit of the converter may cause the rectifier to operate in a field weakening mode at high frequency; only unity AC power factor operation is considered in this section.

\subsection{Voltage oriented control}

An overview of the voltage oriented control (VOC) DC voltage regulator is shown in Fig. 5. The VOC uses the well-known amplitude invariant Clarke (between the three phase system and the stationary coordinates, $\alpha \beta$ ) and the Park transform (from $\alpha \beta$ synchronous rotating coordinates, $d q$ ) to translate the three-phase voltage and current into $d q$ equivalents. 


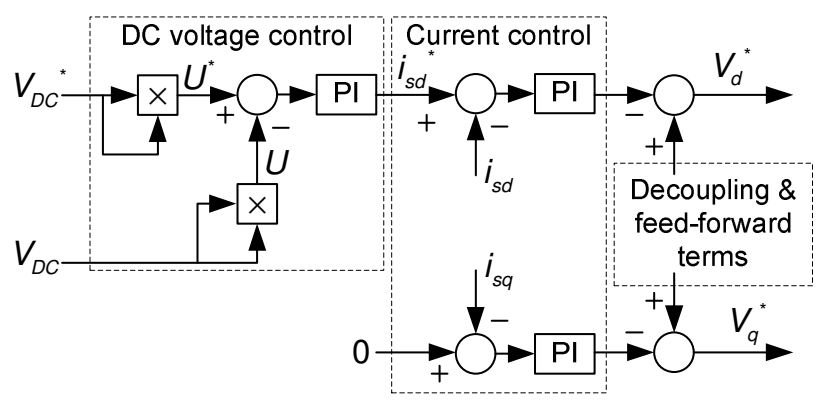

Figure 5. Voltage oriented DC voltage control overview.

The control has two inner current regulation loops to give a fast transient response, with a slower outer DC voltage regulation loop. The reference voltages may be used directly with the averaged-value models, or used in a PWM modulator to determine the switch signals for the switched model.

The back emf is used to determine the control reference frame orientation angle using a phase lock loop and so the d-axis and q-axis components of back emf are equal to $E_{d}=|E|$ and $E_{q}=$ 0 . At unity AC supply power factor the AC current will be in phase with the back emf, $E$, and so $I_{s d}=\left|I_{s}\right|$ and $I_{s q}=0$. Therefore the d-axis current is used to regulate the DC voltage of the rectifier, and the q-axis current is used to ensure unity AC supply power factor.

The d-axis and q-axis components of the rectifier AC circuit in the synchronous rotating reference frame, from Fig. 2 are:

$$
\begin{aligned}
& E_{d}=V_{d}+I_{s d}\left(R_{s}+s L_{s}\right)-j \omega L_{s} I_{s q} \\
& E_{q}=V_{q}+I_{s q}\left(R_{s}+s L_{s}\right)+j \omega L_{s} I_{s d}
\end{aligned}
$$

For tuning of the current regulation the back emf terms can be treated as a disturbance and neglected from (12) and (13) together with the cross-coupling terms, providing these components are summed with the controller output, as shown in Fig. 5. Assuming the use a of PI controller then a simple method is used to identify the tuning gains where the system plant, determined from (12) or (13), is compared to the classic second order differential equation as this yields separate equations for the PI controller gains;

$$
\begin{aligned}
& k_{p-c}=R_{s}-2 \zeta \omega_{n} L_{s} \\
& k_{i-c}=-\omega_{n}^{2} L_{s}
\end{aligned}
$$

For the tuning of the system detailed in Table 1, a damping factor, $\zeta$, of 0.7 and a natural frequency, $f_{n}$, of $0.8 \mathrm{kHz}, k_{p-c}$ is -2.81 and $k_{i-c}$ is $-10.1 \mathrm{k}$. From Bode plots, the system has a crossover frequency of $1.2 \mathrm{kHz}$ and a phase margin of $65.1^{\circ}$.

The reference q-axis current is often set to zero as this enables unity AC supply power factor. A separate control loop is used to determine the reference $\mathrm{d}$-axis current required for the desired DC voltage.

The DC power of the rectifier, (16), can be determined by considering Fig. 2 assuming a resistive load.

$$
P_{d c}=\frac{c_{d c}}{2} \frac{d v_{d c}^{2}}{d t}+\frac{V_{d c}^{2}}{R_{\text {load }}}
$$

The AC power of the rectifier, for the amplitude invariant Clarke transform with orientation of the control to the back emf, is:

$$
P_{a c}=\frac{3}{2}\left(E_{d} I_{s d}+E_{s q} I_{s q}\right)=\frac{3}{2}\left(|E| I_{s d}\right)
$$

Then assuming a lossless converter (only when tuning the DC voltage loop) and so $P_{a c}=P_{d c}$, then as the back emf is slowly varying with time, a transfer function can be developed for the system:

$$
G_{v}(s)=\frac{V_{d c}^{2}}{I_{s d}}=\left(\frac{3|E|}{s C_{d c}+\frac{2}{R_{\text {load }}}}\right)
$$

The transfer function (18) involving $V_{d c}^{2}$ is not linear, however, we can make the transfer function linear by choosing a new state variable, $U$, which equals $V_{d c}^{2}$, so:

$$
G_{u}(s)=\frac{U}{I_{s d}}=\left(\frac{3|E|}{s C_{d c}+\frac{2}{R_{\text {load }}}}\right)
$$

Eq. (19) contains two parameters which may vary during the simulation time, back emf and the load resistor. Bode plots have been used to determine that the low load point has the highest gain at low frequency which is likely to be within the bandwidth of the controller; this operating point is used to design the $V_{d c}^{2}$ control.

A simple method is used to tune the PI gains, similar to that used to design the current regulation, where the system is compared to the classic second order differential equation as this yields separate equations for the PI controller gains $k_{p-v}$ and $k_{i-v},(20)$ and (21) respectively.

$$
\begin{aligned}
& k_{p-v}=\left(2 \zeta \omega_{n}-\frac{2}{C_{d c} R_{\text {load }}}\right) \frac{C_{d c}}{3|E|} \\
& k_{i-v}=\frac{C_{d c} \omega_{n}^{2}}{3|E|}
\end{aligned}
$$

The tuning of the PI controller is demonstrated for the system detailed in Table 1. The damping factor, $\zeta$, is set to 0.7 and the natural frequency, $f_{n}$, is $20 \mathrm{~Hz}$. From (20), $k_{i-v}=0.06$ and from (21), $k_{p-v}=0.651 \mathrm{~m}$ for a $500 \Omega$ load. The cross-over frequency for a $7.29 \Omega$ load is $8.33 \mathrm{~Hz}$ with a phase margin of $111^{\circ}$, and for a $500 \Omega$ load the cross-over frequency is $30.24 \mathrm{~Hz}$ with a phase margin of $65.58^{\circ}$.

\subsection{Predictive control fixed switching frequency}

Predictive current fixed frequency (PCFF) [5] control is designed to enable the phase current to change from its present value to the new desired value in a single switching cycle. The new current reference is $i_{c z}$, the present value of phase current is $i_{s z}$ and so the required rate-of-change of phase current to achieve the new reference value in one switching cycle, $T_{s w}$, is:

$$
\frac{d i_{S Z}}{d t}=\frac{i_{c Z}-i_{S Z}}{T_{S w}}
$$

Equation (22) can be used in the equation for the AC circuit, from Fig. 2, to determine the converter mid-point voltage, $v_{z}$. The converter mid-point voltage can then be scaled for use in 
the PWM modulator, or applied directly to the averaged-value models.

The required $\mathrm{AC}$ current is often sinusoidal and to enable unity AC power factor the AC current should be in phase with the back emf. The magnitude of the AC current is determined by a DC voltage regulator with a feed-forward load term. The PI values in the DC voltage controller are set for maximum disturbance rejection where the DC voltage response for the maximum load change was examined for a range of different controller values. The final controller values are $k_{p-p c f f}=$ 0.65 and $k_{i-p c f f}=40$, which for a $9.5 \mathrm{~kW}$ load step from $0.5 \mathrm{~kW}$ to $10 \mathrm{~kW}$ results in a $-42.2 \mathrm{~V}$ deviation in DC voltage which is within the $-70 \mathrm{~V}$ limit of MIL-Std704F.

\subsection{Predictive direct power control}

The objective of a predictive direct power control (PDPC) [6] is to force the instantaneous active and reactive power in the rectifier circuit to equal the reference values at each switching period, $T_{s w}$. The methodology for determining the PDPC algorithm is given in [6] and is not repeated here. The rectifier input voltage vector during each switching cycle, assuming the fundamental frequency is much less than the switching frequency, is determined using a linear extrapolation between the present and predicted future real and reactive power reference values. The real power reference value is determined by a DC voltage controller and the reactive power reference value is used to set the AC supply power factor and so $Q_{S}^{*}$ is zero.

As in the PCFF scheme, a PI control is used in the DC voltage controller. Again the maximum load condition was used to set the PI tuning values. The final control values were set at $k_{p-p d p c}=0.4$ and $k_{i-p d p c}=50$, which for a $9.5 \mathrm{~kW}$ load step from $0.5 \mathrm{~kW}$ to $10 \mathrm{~kW}$ causes a $-43.2 \mathrm{~V}$ deviation in $\mathrm{DC}$ voltage which is well within the MIL-Std704F limit.

\subsection{Controller comparison}

Fig. 6 compares the performance of the VOC, PFCC and PDPC for the circuit parameters listed in Table 1 and the device parameters in Table A.1. Only the enhanced (lossy) averagedvalue model is used in this comparison to enable the circuit efficiency to be evaluated and to also enable the controller design, which assumes a lossless, converter to be evaluated. The DC voltage reference is initially $240 \mathrm{~V}$ and is stepped to $270 \mathrm{~V}$ at $0.1 \mathrm{~s}$. The load resistor is initially $145.9 \Omega(500 \mathrm{~W})$, then at $0.2 \mathrm{~s}$ it is stepped to $14.58 \Omega(5 \mathrm{~kW})$, at $0.5 \mathrm{~s}$ it returns to $145.9 \Omega$ and it is stepped to $7.29 \Omega(10 \mathrm{~kW})$ at $0.8 \mathrm{~s}$. To demonstrate the regenerative capability of the model a $48 \mathrm{~A}$ $(13 \mathrm{~kW})$ constant current is injected into the DC circuit at $1.1 \mathrm{~s}$. All controllers are regulating the DC bus voltage while ensuring unity AC supply power factor.

The PDPC is the only method tested that meets the MILStd704F for allowable DC voltage deviation; the VOC exceeds the upper $330 \mathrm{~V}$ limit on the load decrease steps and the lower $200 \mathrm{~V}$ limit during the large load increase step as shown in Fig. 6.a, whereas the PCFF exceeds the standards when the power flow reverses at $1.1 \mathrm{~s}$. The PCFF performs well for the load changes, offering only slightly higher voltage deviations with a longer settling time when compared to the PDPC. Fig. 6.b shows AC current for two short time periods to illustrate the detail of the different controller responses; on the scale in Fig. 6.b no difference is noticeable between the $\mathrm{AC}$ currents which are all overlaid. The left hand plot in Fig. 6.b shows AC current during the 7.29 $\Omega$ load showing unity AC power factor operation, and the right hand plot is for the regenerative period showing power flow to the AC supply. When the circuit is controlled using the PDPC algorithm the circuit efficiency is $98.4 \%$ on the highest load of $7.29 \Omega(10 \mathrm{~kW})$, and $98.2 \%$ during regeneration.

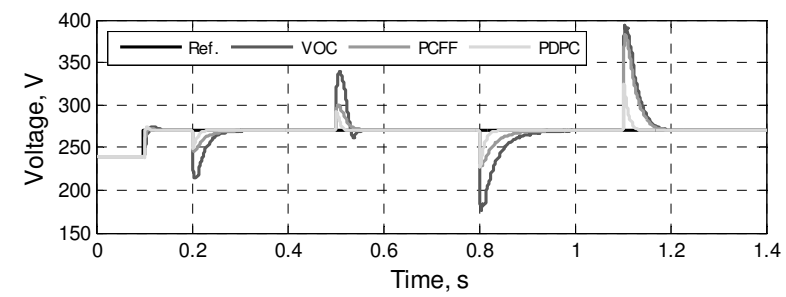

a. DC voltage
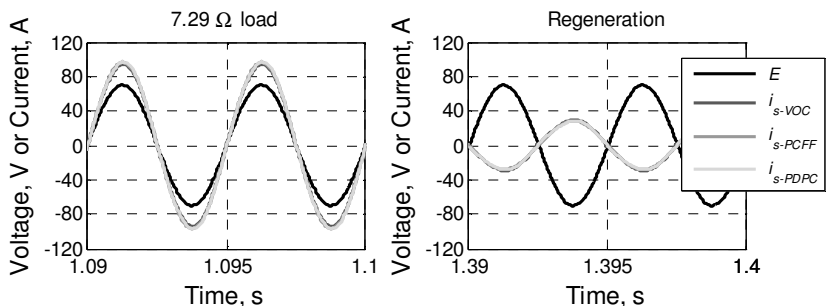

b. Back emf and AC current

Figure 6. Key waveforms for VOC, PCFF and PDPC controlled enhanced (lossy) averaged-value models at $200 \mathrm{~Hz}$.

Fig. 7 shows simulation results for the same controllers, test conditions and circuit / device parameters as used in Fig. 6. The back emf fundamental frequency is increased to $300 \mathrm{~Hz}$ and the back emf magnitude is $105 \mathrm{~V}$. Again only the enhanced (lossy) averaged-value model is used in this comparison to enable the efficiency to be evaluated. All controllers are regulating the DC bus voltage while ensuring unity AC supply power factor.

Both the PDPC and PFCC meet the MIL-Std704F allowable voltage deviation limits for the load step events. At $300 \mathrm{~Hz}$ fundamental frequency the PFCC results in smaller voltage deviations in Fig. 7.a and a shorter settling time than the PDPC, which is opposite to the $200 \mathrm{~Hz}$ results in Fig. 6.a. The DC voltage transient shown in Fig. 7.a at $1.1 \mathrm{~s}$ when the PFCC method is used exceeds the MIL-Std-704F limit, whereas the DC voltage transient from the PDPC technique is within the limit. The VOC DC voltage exceeds the standards on the large power increase step and the power reversal. All controllers enable unity AC power factor performance as shown in Fig. 7.b; on the scale in Fig. 7.b no difference is noticeable between the AC currents which are all overlaid. The circuit efficiency for the PDPC method is $98.62 \%$ on the highest load of $7.29 \Omega$ $(10 \mathrm{~kW})$, and $98.8 \%$ during regeneration. 


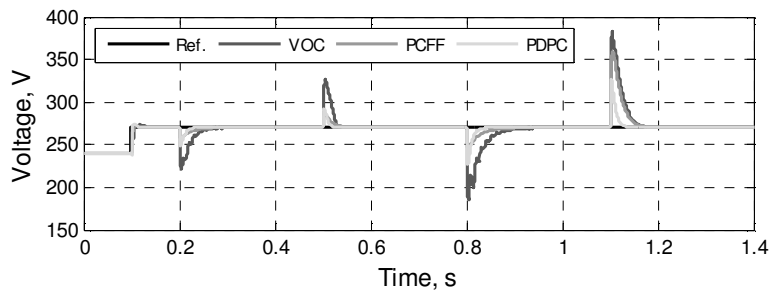

a. DC voltage
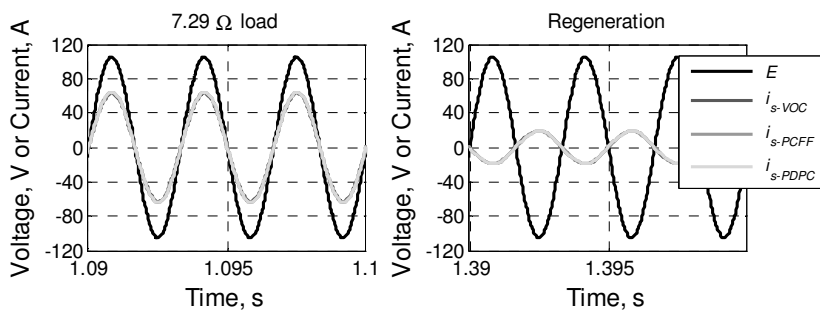

b. Back emf and $\mathrm{AC}$ current

Figure 7. Key waveforms for VOC, PCFF and PDPC controlled enhanced (lossy) averaged-value models at $300 \mathrm{~Hz}$.

\section{Conclusions}

An ideal averaged-value model for the three-phase PWM rectifier was enhanced to include IGBT and diode conduction voltage drops, switching losses, dead-time and overmodulation, to enable the efficiency of the PWM rectifier to be determined for power management studies. The averagedvalue models were validated by a fully-switched model for different load points and AC circuit parameters.

Three different DC voltage controllers, VOC, PFCC and PDPC, have been investigated with both model predictive controllers, the PFCC and the PDPC, resulting in DC voltage transients well within the MIL-Std-704F limits for the load transients examined. Only the PDPC method resulted in acceptable DC voltage transients when the power flow reversed to demonstrate regeneration. The use of the enhanced (lossy) averaged-value model enables the circuit efficiency to be evaluated over the different load conditions.

More generally the work in this paper illustrates the importance of considering the PWM rectifier efficiency when designing on-board power networks to ensure the appropriate system and component sizing. The PWM rectifier control has a significant influence on the system power quality and both the architecture and tuning must be carefully designed for the specific operation range of the system. Further work on the control includes parameter sensitivity of all methods considered.

\section{Acknowledgements}

The research leading to these results has received funding from the European Community's Seventh Framework Programme (FP7/2007-2013) for the Clean Sky Joint Technology Initiative under grant agreement $n^{\circ} 278407$.

\section{References}

[1] X. Roboam, B. Sareni, A.D. Andrade, "More Electricity in the Air: Toward Optimized Electrical Networks Embedded in More-Electrical Aircraft," IEEE Ind. Elec. Mag., vol.6, no.4, pp.6-17, Dec. 2012.

[2] Department of Defense (United States of America) Interface Standard, Aircraft Electric Power Characteristics, MIL-STD704F, Mar. 2004.

[3] L. Shen, G. Asher, G, P. Wheeler, S. Bozhko, "Optimal LCL filter design for 3-phase Space Vector PWM rectifiers on variable frequency aircraft power system," European Conference on Power Electronics and Applications (EPE), pp.1-8, 2013.

[4] Y. Zhihong, D. Boroyevich, C. Jae-Young, F.C. Lee, " Control of circulating current in two parallel three-phase boost rectifiers," IEEE Trans. on Power Electronics, vol.17, no.5, pp.609-615, Sep 2002.

[5] R. Wu, S.B. Dewan, G.R. Slemon, "Analysis of a PWM AC to DC voltage source converter under the predicted current control with a fixed switching frequency," IEEE Trans. on Ind. App., vol. 27, pp. 756-764, 1991.

[6] A. Bouafia, J.P. Gaubert, F. Krim, "Predictive Direct Power Control of Three-Phase Pulse Width Modulation (PWM) Rectifier Using Space-Vector Modulation (SVM)," IEEE Trans. on Power Electronics, vol. 25, pp. 228-236, 2010.

[7] R.W. Erickson, D. Maksimovic, 'Fundamentals of Power Electronics,' Kluwer Academic Publishers, $2^{\text {nd }}$ edn, 2001.

[8] Dawin "Half-Bridge" IGBT DL2G75SH6N 600 V 100 A datasheet, http://www.datasheetarchive.com/dl/DatasheetsUD9/DSARS0049402.pdf, accessed Jan. 2014.

\section{Appendix A}

\begin{tabular}{|c|c|c|}
\hline Parameter description & Symbol & Value \\
\hline Diode threshold voltage & $v_{\text {th-diode }}$ & $1.35 \mathrm{~V}$ \\
\hline Diode resistor & $R_{\text {diode }}$ & $6.7 \mathrm{~m} \Omega$ \\
\hline IGBT threshold voltage & $v_{t h-I G B T}$ & $1.2 \mathrm{~V}$ \\
\hline IGBT resistor & $R_{I G B T}$ & $1.25 \mathrm{~m} \Omega$ \\
\hline Switching frequency & $f_{S W}$ & $10 \mathrm{kHz}$ \\
\hline Dead time & $D$ & $2 \mu \mathrm{s}$ \\
\hline Saturation limit for PWM & - & 0.95 \\
\hline Turn on energy & $E_{O N}$ & $1.4 \mathrm{~mJ}$ \\
\hline Turn off energy & $E_{O F F}$ & $2.6 \mathrm{~mJ}$ \\
\hline $\begin{array}{c}\text { Voltage test condition for the } \\
\text { device energy }\end{array}$ & $V_{D C-N o m}$ & $300 \mathrm{~V}$ \\
\hline $\begin{array}{c}\text { Current test condition for the } \\
\text { device energy }\end{array}$ & $i_{N o m}$ & $75 \mathrm{~A}$ \\
\hline
\end{tabular}

Table A.1. Enhanced PWM rectifier parameter values for Dawin 600 V 100 A IGBT [8]. 